\title{
The Hybrid City Bus Ride Simulation Analysis Based on ADAMS/Car
}

\author{
Kan $\mathrm{Hu}^{1, \mathrm{a}}$, Zuoqiang Dai ${ }^{2, \mathrm{~b}}$, Tiezhu Zhang ${ }^{3, \mathrm{c}}$ \\ ${ }^{1,2,3}$ School of Qingdao University, Qingdao 266071, China \\ a694937470@qq.com, bdaizuoqiangqdu@163.com, cqdzhangtz@163.com
}

\begin{abstract}
Keywords: Ride Performance; Virtual prototyping model; Random pavement; Pulsed pavement.
\end{abstract}
\begin{abstract}
Research on the hybrid electric city bus which is produced by a company, using virtual prototyping technology in the simulation software ADAMS/Car to establish the vehicle dynamics simulation model and road simulation model. And the vehicle model for the random road input ride performance simulation and the impulse road input ride performance simulation analysis. The simulation results of two different random road surfaces are analyzed, in the normal speed range of the vehicle ride performance is good, no adverse effects on the passengers.
\end{abstract}

\section{Introduction}

When the vehicle is traveling on the road, because of the pavement surface roughness will cause the vibration of the vehicle,which will impact on passengers or goods, results in the decrease of passengers ride comfort or the damage to the goods. Vehicle ride performance is mainly refers to the vehicle in the process of driving, keeping vibration and impact generated by the vehicle within certain limits[1]. Ride performance is one of the main property of the vehicle, it will not only have a direct impact on the passenger comfort and safety of the goods transport, also indirectly affects the vehicle's fuel economy and transportation efficiency[2]. Ride performance main object of study is "the road-Vehicle" system, in this system, the primary input is the road surface unevenness, it through the vehicle's tires and suspension damping and elastic damping element is transmitted to the vehicle body filter, thus affecting passenger comfort and the safety of the goods. So the ride performance of vehicle research become the main research direction of modern automobile design personnel.

In a traditional vehicle ride performance test, through real vehicle road test, and then install special measuring instrument to get the data we need. Now with the development of computer simulation technology, through using a mechanical system dynamics software ADAMS can be achieved three-dimensional simulation model of the vehicle on the computer, and the dynamic analysis. You can also easily modify the different parameters and quickly visual observation of the state of motion of the vehicle, dynamic simulation result data, as much as possible to reduce the production cost, shorten the design cycle, more realistic real situation.

The establishment of the vehicle simulation model.Adams/car module is a tool about modeling and simulation which is based on the template and the subsystem, users can easily and quickly create a combination of suspension and vehicle assembly in standard mode. Before the vehicle ride performance simulation analysis, we need to create a virtual prototype of the vehicle to meet the requirements[3]. Vehicle combinations used for the analysis requires at least front and rear suspension, front and rear wheels, steering and vehicle body subsystem. And if you want to build a complete virtual prototype simulation model of vehicle, in addition to the above subsystem, the corresponding brake system and powertrain is needed.

The vehicle front and rear suspension model are all non-independent suspension. According to the actual structure of the suspension provide by enterprise, using the suspension structure template of ADAMS/Car, modifying the template structure by size and location, and according to the parameters such as the actual quality and moment of inertia have a appropriately simplified about the actual front and rear suspension structure, the city's electric bus front suspension structure consists of control arm, transverse stabilizer bar, tie rods, steering knuckle arm triangle, shock absorber and other several parts. The rear suspension structure consists of shock absorbers, rear axle, 
longitudinal thrust rod, wheel hub, bushings and other several parts.

Tire is one of the important components of the vehicle, for the vehicle simulation model, the tire model is also one of the most important parts[4]. Because of the tire is composed of synthetic materials such as rubber, tire cord layer, so that the tire has a highly non-linear, compressibility, anisotropy and viscoelasticity, lead to the physical model is more complicated[5]. As there are many tire modeling method, the data requirements, data output and precision of the model is not exactly same. More importantly, the modeling accuracy of the tire also directly affect the vehicle dynamics modeling accuracy, so tire choice must be consistent with the model simulation requirements. In this paper, the model chosen PAC2002 tire model, according to the actual size of the tire, by modifying the size and the characteristic parameters of the tire model PAC2002 ADAMS/Car provided, to establish the hybrid city bus tire model.

Vehicles in the process of driving, the drivers need to be judged of the driving conditions, according to their own consciousness to change the direction of the vehicle. Vehicle steering system is a series of devices that is used to maintain or change the traveling direction of the vehicle. Commonly used vehicle steering system with a mechanical steering systems and power steering systems.

In this paper, the vehicle steering system is recirculating ball steering system, the steering system consists of a steering wheel, steering column, the steering column, the steering intermediate shaft, steering shaft, steering gear, steering arm, tie rods and knuckle arms.

The power model in the vehicle play a major role in providing power, the shape does not affect of the simulation results. Therefore, this article used engine model chosen ADAMS/Car model as provided, modified by the model parameters and establish the corresponding communication, get the desired engine model.

Brake system in the vehicle simulation mainly control and change the speed, and no other special effects on vehicle simulation. Therefore, this article uses the ADAMS/Car brake system template, by modifying the template parameters to get the required brake system model.

After establishing each part of the template, they need to be composed of various subsystems. In order to make each subsystem can accomplish the required movement, those subsystems need to be assembled and debugged in the standard model. So that to form a complete system can be coordinated interacted between the each subsystem.

In this paper, we will select the Four Post Test Rig to have the ride performance test assembly program. Based on Four Post Test Rig vehicle simulation model is shown in Fig.1.

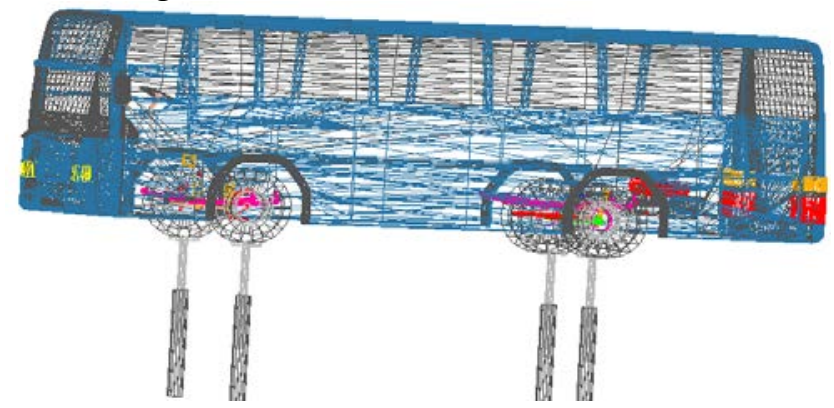

Fig.1 Based on Four Post Test Rig vehicle simulation model

The vehicle ride performance simulation test analysis.In the study of vehicle ride performance simulation, construct the pavement structure is an important aspect[6]. When the road surface roughness as the input source, the ADAMS/Car Ride be required to provide the space power spectral density Ge, the velocity power spectral density Gs and the acceleration power spectral density $\mathrm{Ga}$. Set the space power spectral density $\mathrm{Ge}=0.1$, the velocity power spectral density $\mathrm{Gs}=35$ and the acceleration power spectral density $\mathrm{Ga}=0.3$, the generated pavement is equal of the cement pavement. By the road profile generator to generate random road profile as shown in Fig.2. 


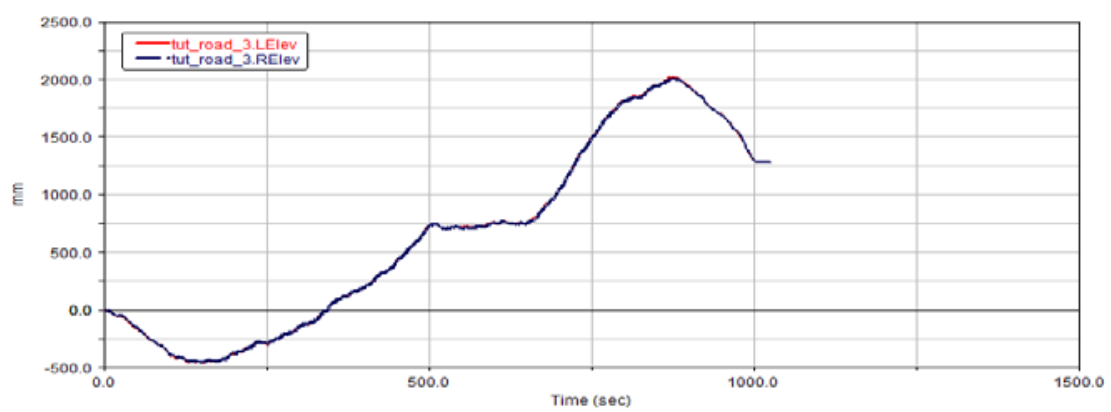

Fig.2 Random road profile

For the random road input, according to the vehicle speed range predetermined in GB/T4970-1996, on the speed of $40,50,60,70,80,90,100 \mathrm{~km} / \mathrm{h}$ to have the random road simulation. We choice the sampling interval is $0.05 \mathrm{~m}$, wavelength correlation length is $5 \mathrm{~m}$ and simulation time is $5 \mathrm{~s}$, we will get the chassis vertical acceleration simulation curve in different speed. As shown in Fig.3.

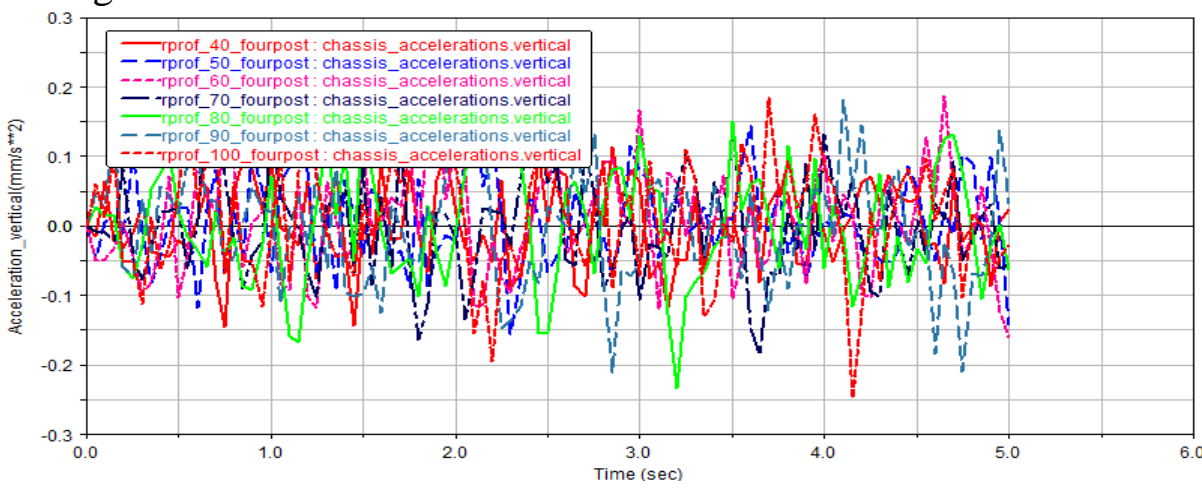

Fig.3 Chassis vertical acceleration simulation curve in different speed

According to ISO2631, relationship between the total weighted value of the vehicle vertical acceleration root mean square value and the subjective feelings as shown in Table 1[7]. Due to not include seat and human body system in this model, the human body actually feel the vibration through the seat cushion of attenuation and the seat of damping is less than the vibration of the body, it can according to the real vehicle experiment data, with the acceleration of the root mean square value of the vehicle seat bottom in the vertical direction to approximate conversion. General seats corresponding to the root mean square value of the acceleration of the body is more than 1.4 times the seat of human feelings. Thus it can calculate the human feelings about the root mean square value of weighted acceleration under different speed are shown in Table 2.

Table 1 Vehicle vertical acceleration root mean square value and the subjective feelings

\begin{tabular}{cc}
\hline Root mean square value of weighted acceleration $\mathrm{a}_{\mathrm{w}}\left(\mathrm{m} / \mathrm{s}^{2}\right)$ & $\begin{array}{c}\text { Subjective feelings of } \\
\text { passengers }\end{array}$ \\
\hline$<0.315$ & No feeling of discomfort \\
$0.315 \sim 0.63$ & Slightly uncomfortable \\
$0.5 \sim 1.0$ & Some uncomfortable \\
$0.8 \sim 1.6$ & Uncomfortable \\
$1.25 \sim 2.5$ & Very uncomfortable \\
$>2$ & Extremely uncomfortable \\
\hline
\end{tabular}


Table 2 Human feelings about the root mean square value of weighted acceleration under different speed

\begin{tabular}{cc}
\hline Vehicle speed $(\mathrm{km} / \mathrm{h})$ & $\mathrm{a}_{\mathrm{w}}\left(\mathrm{m} / \mathrm{s}^{2}\right)$ \\
\hline 40 & 0.56 \\
50 & 0.64 \\
60 & 0.67 \\
\hline 70 & 0.73 \\
80 & 0.81 \\
90 & 0.87 \\
100 & 0.94 \\
\hline
\end{tabular}

We will know from table 1 and table 2, when the vehicle speed is $40 \mathrm{~km} / \mathrm{h}$, passengers will be slightly uncomfortable feeling; when the vehicle speed is $50 \sim 70 \mathrm{~km} / \mathrm{h}$, the occupant will feel a bit uncomfortable; the speed at $80 \sim 100 \mathrm{~km} / \mathrm{h}$ occupant will feel uncomfortable.

The ride comfort of the automobile under the impulse excitation is another important basis to evaluate the ride performance of the vehicle[8]. This paper evaluates the ride performance of the vehicle from the impact of the vehicle passing through the single bump. According to the national standard GB/T5902-1986, "the impulse input test method for vehicle ride performance", a pulse road surface for vehicle ride comfort simulation is established. In this paper, the pulse road surface is the single bump, the road height is $35 \mathrm{~mm}$, the width is $50 \mathrm{~mm}$, as shown in Fig. 4 .

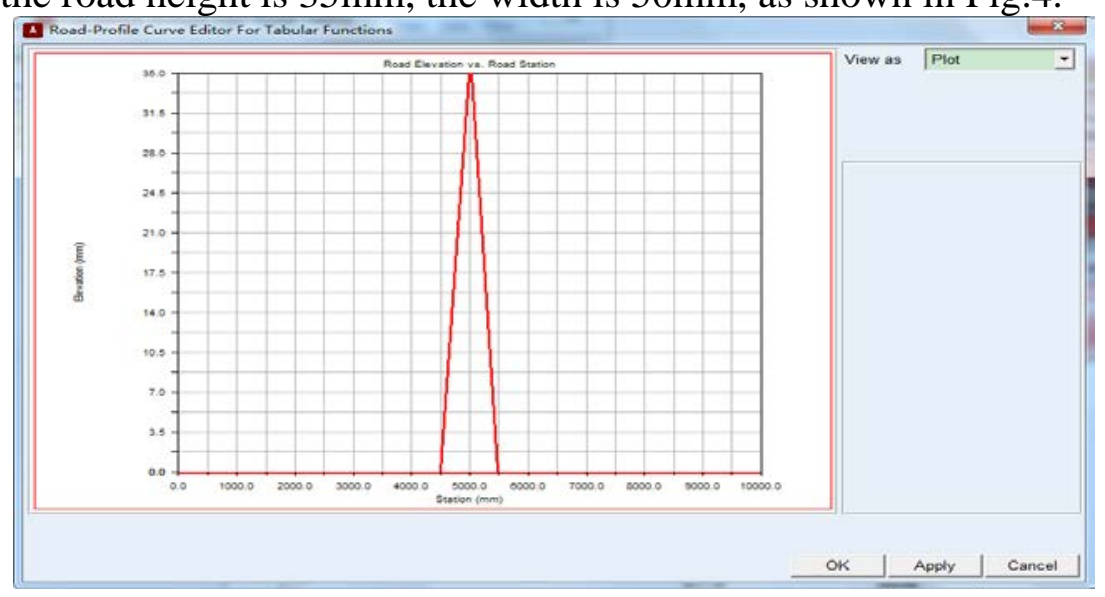

Fig.4 Pulse pavement profile

According to the national standard GB/T5902-1986"vehicle ride performance pulse input test method", the car is $10,20,30,40,50,60,70 \mathrm{~km} / \mathrm{h}$ uniform speed through the above bump. The vehicle's ride comfort evaluation is carried out with the absolute value of the maximum vertical acceleration response of the vehicle body. When the vehicle speed is $10,20,30,40,50,60,70 \mathrm{~km} / \mathrm{h}$ through the above bump, the vertical acceleration of the body as shown in Fig.5.

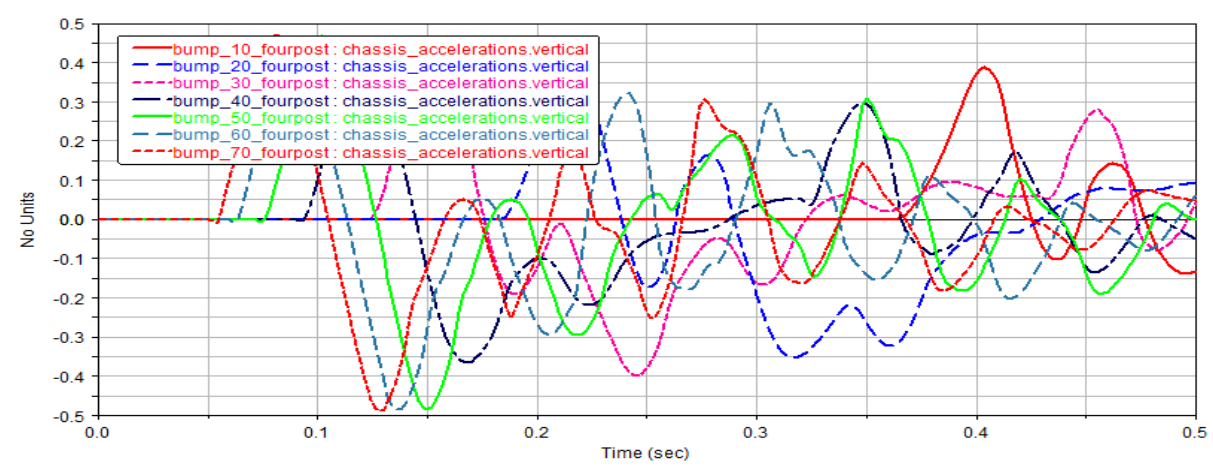

Fig.5 Body vertical acceleration under the pulse pavement

In the new draft of the ISO2631, the following evaluation indexes are put forward for the ride performance test of pulse input[9]. The absolute value of maximum acceleration response when the seat surface passing to the occupant is greater than $43.02 \mathrm{~m} / \mathrm{s}^{2}$, it will harmful to human health; when 
the absolute value of maximum acceleration response less than $31.44 \mathrm{~m} / \mathrm{s}^{2}$, no harm to health; when it is between $31.44 \mathrm{~m} / \mathrm{s}^{2}$ and $43.02 \mathrm{~m} / \mathrm{s}^{2}$, have a certain impact on health. The figure12 shows that the vehicle model passing the bump, the maximum acceleration response is much lower than $31.44 \mathrm{~m} / \mathrm{s}^{2}$, it will not have an impact on occupant health.

\section{Summary}

The impulse input simulation analysis of the vehicle ride performance shows that the hybrid electric city bus is not harmful to the health of the crew when the vehicle speed is less than $60 \mathrm{~km} / \mathrm{h}$ through the standard bump. The vehicle ride comfort random input simulation analysis show that when the speed is lower than $40 \mathrm{~km} / \mathrm{h}$ is better, when speed is above $50 \mathrm{~km} / \mathrm{h}$ is not very ideal. The simulation results provide a reference for the evaluation, research and improvement of the vehicle ride performance.

\section{Acknowledgements}

This work was financially supported by the National Science-technology Support Plan Projects"The key technology and application of lithium ion power battery based on the new high safety diaphragm"under Grant No.2012BAG26B02.

\section{References}

[1] Changle Liu. Analysis of vehicle handling stability and ride performance based on virtual prototype technology[D]. Xi'an: Chang'an University, 2010.

[2] Huibao Xu, Qingyu Zhuang, Hongqiang Xu and so on. Simulation of vehicle ride performance based on virtual prototype technology[J]. Nanjing: Journal of Nanjing Institute of Technology(Natural Science Edition), 2014, 12(2): 14-17.

[3] Jun Chen. MSC.ADAMS technology and engineering analysis Beijing: China Water\&Power Press, 2008.

[4] Yucong Gao. Simulation and analysis of the dynamic performance of passenger car air suspension[D]. Xi'an: Chang'an University, 2013.

[5] Yuhua Sun. Research on the design and characteristics of the system of steering by wire[D]. Chengdou: Xihua University, 2009.

[6] Nan Wang, Enshun Ping, Longshan Yue and so on. Modeling and simulation of vehicle ride performance based on ADAMS/Car Ride[J].Manufacturing Automation, 2010, 32(10): 90-92.

[7] Hui Wei, Jing Yang, Bing Chen and so on. Simulation of vehicle ride performance based on ADAMS/Car[J]. Development \& Innovation of Machinery \& Electrical Products, 2008, 21(6): 100-102.

[8] Xiangting Wang, Ruiqian Zhang, Jun Zhao and so on. Simulation analysis of vehicle ride comfort based on ADAMS[J]. Utomobile Technology, 2013, (12):8-14.

[9] Guoquan Wang. Research on virtual test technology of vehicle ride performance[D]. Beijing: China Agricultural University, 2002. 